\title{
Interactions with PDZ Proteins Are Required for L-Type Calcium Channels to Activate cAMP Response Element- Binding Protein-Dependent Gene Expression
}

\author{
Jason P. Weick, Rachel D. Groth, Ann L. Isaksen, and Paul G. Mermelstein \\ Department of Neuroscience, University of Minnesota, Minneapolis, Minnesota 55455
}

\begin{abstract}
After brief periods of heightened stimulation, calcium entry through L-type calcium channels leads to activation of the transcription factor cAMP response element-binding protein (CREB) and CRE-dependent transcription. Many of the details surrounding the mechanism by which L-type calcium channels are privileged in signaling to CREB, to the exclusion of other calcium entry pathways, has remained unclear. We hypothesized that the PDZ interaction sequence contained within the last four amino acids of the calcium channel $\alpha_{1 \mathrm{C}}\left(\mathrm{Ca}_{\mathrm{V}} 1.2\right)$ subunit [Val-Ser-Asn-Leu (VSNL)] is critical for L-type calcium channels (LTCs) to interact with the signaling machinery that triggers activity-dependent gene expression. To disrupt this interaction, hippocampal CA3-CA1 pyramidal neurons were transfected with DNA encoding for enhanced green fluorescent protein tethered to VSNL (EGFP-VSNL). EGFP-VSNL significantly attenuated L-type calcium channel-induced CREB phosphorylation and CRE-dependent transcription, although somatic calcium concentrations after stimulation remained unchanged. The effect of EGFP-VSNL was specific to the actions of L-type calcium channels, because CREB signaling after NMDA receptor stimulation remained intact. The importance of the PDZ interaction sequence was verified using dihydropyridine (DHP)-insensitive $\alpha_{1 \mathrm{C}}$ subunits. Neurons transfected with $\alpha_{1 \mathrm{C}}$ lacking the terminal five amino acids (DHP-LTCnoPDZ) exhibited attenuated CREB responses in comparison with cells expressing the full-length subunit (DHP-LTC). Collectively, these data suggest that localized calcium responses, regulated by interactions with PDZ domain proteins, are necessary for L-type calcium channels to effectively activate CREB and CRE-mediated gene expression.
\end{abstract}

Key words: NIL-16; CREB; NFAT; L-type calcium channel; $\alpha_{1 \mathrm{C}}$; $\mathrm{Ca}_{\mathrm{V}} 1.2$; CIPP; NMDA

\section{Introduction}

Activity-dependent gene expression is critical for the changes that occur during development, learning and memory, induction of chronic pain, and the use of abusive drugs (Morgan and Curran, 1991; Bonni and Greenberg, 1997; Nestler and Aghajanian, 1997; Lanahan and Worley, 1998; Melzack et al., 2001). The transcription factor cAMP response element-binding protein (CREB) plays an important role in each of these processes (Finkbeiner et al., 1997; Ji and Rupp, 1997; Carlezon et al., 1998; Milner et al., 1998; Silva et al., 1998; Anderson and Seybold, 2000). Within the hippocampus and other brain regions, CREB activation after brief stimulation ( $\leq 3 \mathrm{~min}$ ) is primarily mediated by calcium entry via L-type calcium channels (with a smaller component attributable to NMDA receptors) (Sheng et al., 1991; Bading et al., 1993; Deisseroth et al., 1996; Mermelstein et al., 2000). Calcium influx through L-type channels activates calmodulin $(\mathrm{CaM})$, leading to phosphorylation of CREB on $\mathrm{Ser}^{133}$ by CaMdependent protein kinases (Enslen et al., 1995; Tokumitsu et al., 1995; Bito et al., 1996; Ahn et al., 1999; Ho et al., 2000; Ribar et al.,

\footnotetext{
Received Sept. 4, 2002; revised Dec. 31, 2002; accepted Jan. 29, 2003.

This work was supported by National Institutes of Health (NIH) Grant NS41302 and a Whitehall Foundation grant (P.G.M.). R.D.G. is supported by NIH Training Grant DA07234. We thank Drs. Linda Boland, Eric Newman, Harry Orr, and Kevin Wickman for their scientific input; Drs. Stan Thayer and Yuriy Usachev for their assistance with the photometry studies; Dr. Chris Gomez, Robert Raike, and Holly Kordasiewicz for providing COS cells; and Bryan Becklund, Marissa Iden, and Kathryn Klammer for their technical support. We thank Drs. Michael Greenberg and Ricardo Dolmetsch for the DHP-LTC construct and Dr. Cornelia Kurschner for the NIL-16 plasmid.

Correspondence should be addressed to Paul G. Mermelstein, Department of Neuroscience, University of Minnesota, 6145 Jackson Hall, 321 Church Street Southeast, Minneapolis, MN 55455. E-mail: pmerm@umn.edu. Copyright $\odot 2003$ Society for Neuroscience $\quad 0270-6474 / 03 / 233446-11 \$ 15.00 / 0$
}

2000; Kang et al., 2001). Phosphorylation of CREB promotes its interaction with CREB binding protein (CBP) or a similar coactivator, leading to CRE-dependent transcription (Parker et al., 1996). Yet after various forms of stimulation, L-type channels contribute only a small percentage to the overall rise in cytoplasmic calcium (Deisseroth et al., 1998; Dolmetsch et al., 2001). Thus the mechanism by which calcium entry specifically through L-type channels mediates CREB activation is not completely understood.

Several lines of evidence suggest that the localization of L-type channels is an important determinant in their ability to signal to CREB. Using various calcium chelators, a recent study proposed that subcellular microdomains adjacent to the plasma membrane contain the calcium-sensitive signaling machinery necessary for CREB phosphorylation (Deisseroth et al., 1996). To play a privileged role in activity-dependent gene expression, L-type calcium channels would be localized to these regions, to the exclusion of other calcium entry routes. $\alpha_{1 \mathrm{C}}\left(\mathrm{Ca}_{\mathrm{V}} 1.2\right)$, the principal subunit of a large proportion of L-type calcium channels expressed in brain, ends with the PDZ interaction sequence Val-Ser-Asn-Leu (VSNL) (Koch et al., 1990; Snutch et al., 1991). VSNL promotes $\alpha_{1 \mathrm{C}}$ interactions with at least two PDZ domain proteins, channelinteracting PDZ domain protein and neuronal interleukin-16 (Kurschner et al., 1998; Kurschner and Yuzaki, 1999). Because PDZ domain proteins are critical for linking channels and receptors to specific second messenger systems (Craven and Bredt, 1998; Sheng and Pak, 2000), we hypothesized that the interactions between $\alpha_{1 C}$ and PDZ domain proteins are required for L-type calcium channels to efficiently activate CREB.

Two separate lines of experiments were pursued to test this 
hypothesis. First, VSNL was expressed in hippocampal pyramidal neurons. In theory, VSNL would compete with endogenous L-type calcium channels for the PDZ domain proteins with which $\alpha_{1 \mathrm{C}}$ typically interacts, resulting in the displacement of these channels from the calcium-sensing microdomains normally involved in CREB activation. To visualize VSNL, the peptide was added to the $\mathrm{C}$ terminus of enhanced green fluorescent protein (EGFP-VSNL), generating a fluorescent protein that in many respects would mimic $\alpha_{1 \mathrm{C}}$ localization. Thus, the effect of EGFP-VSNL on L-type calcium channel-dependent CREB signaling was first determined. In the second set of experiments, neurons were transfected with DNA encoding for either fulllength $\alpha_{1 \mathrm{C}}$ subunits that generate dihydropyridine (DHP)insensitive L-type calcium channels (DHP-LTC) (Dolmetsch et al., 2001) or a dihydropyridine-insensitive $\alpha_{1 \mathrm{C}}$ subunit containing a premature stop codon, resulting in the deletion of the PDZ interaction sequence (DHP-LTCnoPDZ). The results from both studies suggest that the VSNL sequence on $\alpha_{1 \mathrm{C}}$ plays a critical role in L-type calcium channel-mediated CREB phosphorylation and CRE-dependent transcription.

\section{Materials and Methods}

Cell culture and transfection. Hippocampal pyramidal neurons from 1- to 2-d-old rats were cultured as described previously (Mermelstein et al., 2000). Briefly, after decapitation and brain removal, the CA3-CA1 region of the hippocampus was isolated in an ice-cold modified HBSS solution containing 20\% fetal bovine serum (FBS) (Hyclone, Logan, UT) and (in mM): $4.2 \mathrm{NaHCO}_{3}, 1$ HEPES, pH 7.35, 300 mOsm. All chemicals were obtained from Sigma (St. Louis, MO) unless stated otherwise. After dissection, the hippocampi were washed and digested for 5 min with 10 $\mathrm{mg} / \mathrm{ml}$ Trypsin (type XI) in a solution that contained (in mM): $137 \mathrm{NaCl}$, $5 \mathrm{KCl}, 7 \mathrm{Na}_{2} \mathrm{HPO}_{4}, 25$ HEPES, and DNase (1500 U), pH 7.2, 300 mOsm. The tissue was washed and then dissociated using a series of Pasteur pipettes of decreasing diameter. The cell suspension was pelleted twice to remove contaminants, plated on $10 \mathrm{~mm}$ coverslips, and allowed to adhere for $15 \mathrm{~min}$ before addition of $2 \mathrm{ml} \mathrm{MEM} \mathrm{(Invitrogen,} \mathrm{Grand} \mathrm{Island,}$ $\mathrm{NY}$ ) containing (in mM): 28 glucose, $2.4 \mathrm{NaHCO}_{3}, 0.0013$ transferrin (Calbiochem, La Jolla, CA), 2 glutamine, 0.0042 insulin, and 10\% FBS, $\mathrm{pH} 7.35,300 \mathrm{mOsm}$. Twenty-four hours after plating, $1 \mathrm{ml}$ of media was replaced with a similar solution containing $4 \mu \mathrm{M}$ cytosine $1-\beta$-Darabinofuranoside and 5\% FBS. Three days later, $1 \mathrm{ml}$ of media was replaced with modified MEM containing 5\% FBS. Media solutions contained $2 \mu \mathrm{g} / \mathrm{ml}$ gentamicin (Invitrogen, Carlsbad, CA) to prevent bacterial growth.

Cultured neurons were transfected 7-9 d in vitro (DIV) using a calcium phosphate-based technique (Graef et al., 1999). African Green Monkey kidney (COS-7) cells and human embryonic kidney (HEK)-293 cells were maintained in a DMEM-F12 solution (Life Technologies) containing $2 \mu \mathrm{g} / \mathrm{ml}$ gentamicin. Transfections were performed at $70-80 \%$ confluency using Lipofectamine 2000 following the manufacturer's instructions (Invitrogen).

DNA subcloning and immunocytochemistry. pEGFP-C1 was obtained from Clontech (Palo Alto, CA). The sequences encoding for VSNL and Ile-Thr-Thr-Leu (ITTL) were inserted into the multiple cloning site using standard procedures and verified by direct sequencing. NIL-16 was a gift from C. Kurschner (Myriad Proteomics); the DHP-LTC construct was a gift from M. Greenberg (Harvard University) and R. Dolmetsch (Stanford University). Generation of the DHP-LTCnoPDZ construct was the result of a single round of QuickChange mutagenesis following the manufacturer's instructions (Stratagene, La Jolla, CA), replacing the DNA sequence that encodes for the final tyrosine immediately before VSNL in $\alpha_{1 \mathrm{C}}$ with a premature stop codon. The mutagenesis was verified by direct sequencing.

For experiments measuring CREB phosphorylation, $\sim 20 \mathrm{hr}$ after transfection, cells were preincubated for $3 \mathrm{hr}$ in a standard Tyrode solution containing $1 \mu \mathrm{M}$ TTX. When applicable, $5 \mu \mathrm{M}$ nifedipine and $25 \mu \mathrm{M}$ D-AP5 (Tocris, Ellisville, MO) were used to block L-type calcium chan- nels and NMDA receptors. KN-93 (2 $\mu$; Calbiochem) was used to block CaM-dependent protein kinases, and the inactive analog KN-92 (10 $\mu \mathrm{M})$ was used because a control. Diltiazem $(100 \mu \mathrm{M})$ was used to block the dihydropyridine-insensitive calcium channels. AP5, nifedipine, KN-93, $\mathrm{KN}-92$, and diltiazem were present $30 \mathrm{~min}$ before and throughout the stimulation. Three minute application of $50 \mu \mathrm{M}$ NMDA was used to initiate NMDA receptor-mediated CREB phosphorylation.

After stimulation, cells were fixed for $20 \mathrm{~min}$ with ice-cold $4 \%$ paraformaldehyde (Electron Microscopy Sciences, Ft. Washington, PA) in PBS containing 4 mm EGTA. Cells were washed three times with PBS and then permeabilized for 5 min with $0.1 \%$ Triton X-100 (VWR, West Chester, PA). After PBS wash, cells were incubated for $0.5 \mathrm{hr}$ at $37^{\circ} \mathrm{C}$ in a PBS-based block solution containing $1 \%$ BSA and $2 \%$ goat serum (Jackson ImmunoResearch, West Grove, PA). Afterward, coverslips were exposed to the primary antibody [1:1000 dilution of the polyclonal antipCREB antibody (Upstate Biotechnology, Lake Placid, NY)] for $1 \mathrm{hr}$ at $37^{\circ} \mathrm{C}$. For detecting $\alpha_{1 \mathrm{C}}$, neurons were fixed for $\sim 12 \mathrm{hr}$ after transfection with EGFP, EGFP-VSNL, or EGFP-ITTL. In these experiments, the preincubation and stimulation steps were omitted, and the primary antibody (1:100; Alomone Labs, Jerusalem, Israel) incubation was performed overnight at $37^{\circ} \mathrm{C}$. After exposure to the primary antibody, cells were washed with PBS and incubated for $1 \mathrm{hr}$ with a Cy3-conjugated secondary antibody (Jackson ImmunoResearch). Cells were washed again and mounted using the anti-quenching reagent Citifluor (Ted Pella, Redding, CA). Acquisition and quantification of fluorescent intensities ( $n=\sim 15$ per group) were determined using a Bio-Rad confocal workstation (MRC 1024) and Metamorph software (version 4.6). Transfected neurons were compared with untransfected cells on the same coverslip, often in the same image. To verify consistency across cover slides, multiple coverslips (two to three) were prepared following the same experimental conditions. Experiments were also replicated multiple times to verify results. Immunocytochemistry on COS-7 cells followed similar protocols. NIL-16 was detected with an antibody (1:100) from PharMingen (San Diego, CA) (Kurschner and Yuzaki, 1999). Expression of DHP-LTC and DHP-LTCnoPDZ was determined with an Xpress antibody (1:1000) from Invitrogen.

For quantification of $\alpha_{1 \mathrm{C}}$ and EGFP-VSNL staining, confocal images were taken under equivalent magnification and laser intensity. In addition, the confocal section that included the primary dendrite was used for analysis. For the analysis of $\alpha_{1 \mathrm{C}}$ clustering, a single fluorescence threshold was set and applied equally across groups to minimize the inclusion of background staining. On the basis of a Gaussian distribution, individual puncta were defined as fluorescent regions of two to six adjacent pixels $(\sim 0.5 \mu \mathrm{m})$, all above the threshold value. Fluorescent regions larger than six pixels were considered to be multiples. The total number of fluorescent aggregations within a $7 \mu \mathrm{m}$ radius from the center of the nucleus was included in the analysis. Because of the inherent differences in transfection level and EGFP expression, no single background threshold could be applied for the quantification of EGFP-VSNL puncta. Thus, individual thresholds were set for each cell, and puncta were counted according to the methods described above. Multiple observers $(n=4)$ performed analyses of each cell without knowledge of experimental hypotheses, and the average counts were used for the final analysis.

Coimmunoprecipitation. HEK-293 or COS-7 cells transfected with NIL-16 and either EGFP or EGFP-VSNL were washed once with $4^{\circ} \mathrm{C}$ PBS and then lysed in ice-cold modified radioimmunoprecipitation (RIPA) buffer without SDS (Harlow and Lane, 1988) that contained (in mM): 1 EDTA, $200 \mathrm{PMSF}, 200 \mathrm{Na}_{3} \mathrm{VO}_{4}$, and $200 \mathrm{NaF}$ plus $1 \mu \mathrm{g} / \mathrm{ml}$ of aprotinin, leupeptin, and pepstatin. Cells were collected in $1.5 \mathrm{ml}$ Eppendorf tubes and spun in a microcentrifuge at $14,000 \mathrm{rpm}$ for $10 \mathrm{~min}$. The supernatant was transferred to a separate $1.5 \mathrm{ml}$ tube containing $30 \mu \mathrm{l}$ of protein-G beads and agitated for $1 \mathrm{hr}$ at $4^{\circ} \mathrm{C}$. After centrifugation at $2000 \mathrm{rpm}$ for 2 $\mathrm{min}$, the supernatant was removed and added to a fresh $1.5 \mathrm{ml}$ tube containing $30 \mu \mathrm{l}$ of protein-G beads and $5 \mu \mathrm{g}$ of the anti-NIL-16 antibody. After agitation for $1 \mathrm{hr}$ at $4^{\circ} \mathrm{C}$, the solution was centrifuged at 2000 rpm for $2 \mathrm{~min}$. The pellet was washed three times with RIPA buffer and prepared for Western blotting using commercially available reagents (Invitrogen). After blocking in a Tris-buffered saline solution containing $10 \%$ milk and $1 \%$ BSA, the blot was incubated with a chicken polyclonal 
anti-EGFP antibody (1:1000; Upstate Biotechnology) overnight at $4^{\circ} \mathrm{C}$. Both the primary and secondary antibodies were diluted in Tris-buffered saline containing $1 \%$ milk, $1 \%$ BSA, and $0.1 \%$ Tween 20 . The membrane was washed in $0.1 \%$ Tween-Tris-buffered saline and probed with an anti-chicken-HRP antibody (1:25,000) (Pierce, Rockford, IL) for $1 \mathrm{hr}$ at $25^{\circ} \mathrm{C}$ and then exposed to X-Omat XB-1 film (Kodak, Rochester, NY). Direct loading of the cell lysis solution was used as a positive control for transfection efficiency.

Electrophysiology. Whole-cell patch-clamp recordings of cultured hippocampal neurons ( $\sim 10 \mathrm{DIV}, 24 \mathrm{hr}$ after transfection) were performed at room temperature using standard techniques. Warner GC120T-10 borosilicate glass electrodes (Warner Instrument Corp., Hamden, CT) were pulled on a Flaming/Brown p-97 puller (Sutter Instrument Co., Novato, CA) and fire polished with an MF-830 microforge (Narishige, Hempstead, NY). The intracellular recording solution contained (in mM): $190 \mathrm{~N}$-methyl-D-glucamine, $40 \mathrm{HEPES}, 5$ BAPTA, $4 \mathrm{MgCl}_{2}, 12$ phosphocreatine, $3 \mathrm{Na}_{2} \mathrm{ATP}$, and $0.2 \mathrm{Na}_{3} \mathrm{GTP}$, pH 7.2, $275 \mathrm{mOsm}$. The external recording solution contained (in $\mathrm{mm}$ ): $135 \mathrm{NaCl}, 20 \mathrm{CsCl}, 1$ $\mathrm{MgCl}_{2}, 10$ HEPES, $0.0001 \mathrm{TTX}$, and $5 \mathrm{mM} \mathrm{BaCl}_{2}$. Bath solution contained (in mM): $140 \mathrm{NaCl}, 2 \mathrm{KCl}, 23$ glucose, 15 HEPES, $1 \mathrm{CaCl}_{2}, 2 \mathrm{MgCl}_{2}$, and 0.01 glycine. All reagents were obtained from Sigma except ATP and GTP (Boehringer Mannheim, Indianapolis, IN) and BAPTA (Calbiochem). The junction potential $(<2 \mathrm{mV})$ was not compensated. Recordings were obtained using an Axopatch 200B amplifier (Axon Instruments, Union City, CA) controlled by a PC running pCLAMP software (version 8.0) using a $125 \mathrm{kHz}$ interface. Electrode resistances were $\sim 3 \mathrm{M} \Omega$. The series resistance was compensated $>70 \%$.

Gene expression assay. Cultured neurons ( 7-9 DIV) were transfected with a luciferase-based reporter for CRE- or nuclear factor of activated T-cells (NFAT)-dependent transcription and EGFP or EGFP-VSNL. After transfection, $2 \mu \mathrm{M}$ TTX was added to the media. The next day, cells were washed with DMEM, and half were stimulated for $3 \mathrm{~min}$ in the high $\mathrm{K}^{+}$solutions indicated. For the CRE-luciferase assays, all cells were pretreated for 30 min with $25 \mu \mathrm{M}$ AP5, which was also present during stimulation. Afterward, the original media was supplemented with $2 \mu \mathrm{M}$ TTX and reapplied to the coverslips. Sixteen hours after stimulation, cells were lysed and cellular protein was isolated. Luciferase expression was measured using standard procedures. When measuring the L-type calcium channel component of synaptically mediated NFAT-dependent transcription, half of the neurons were treated with $5 \mu \mathrm{M}$ nifedipine after transfection. As a control for cellular viability, a constitutively active reporter (PBJ5-luciferase) was transfected with either EGFP or EGFPVSNL. In separate experiments, the CRE-luciferase reporter was transfected with either DHP-LTC or DHP-LTCnoPDZ. The following day, 25 $\mu \mathrm{M}$ AP5 and $5 \mu \mathrm{M}$ nifedipine were added to the cell media. Half of the coverslips were also exposed to $100 \mu \mathrm{M}$ diltiazem. Thirty minutes later, coverslips were stimulated with a modified cell media solution containing $20 \mathrm{mM} \mathrm{K}^{+}$and either AP5 and nifedipine or AP5, nifedipine, and diltiazem. Three hours later, cells were lysed and luciferase expression was measured. Luciferase expression was not significantly different across groups in unstimulated neurons. All experiments were replicated to verify results.

Calcium photometry. Internal calcium concentrations were determined using the calcium indicator Indo-1 (Grynkiewicz et al., 1985), using methods published previously (Werth et al., 1996). Briefly, $\sim 24 \mathrm{hr}$ after transfection, cells were loaded with $2 \mu \mathrm{M}$ Indo- 1 AM ester at room temperature for $40 \mathrm{~min}$. During recording, EGFP- and EGFP-VSNLtransfected cells were superfused with a Tyrode solution containing $1 \mu \mathrm{M}$ TTX and $25 \mu \mathrm{M}$ AP5 at a rate of $1-2 \mathrm{ml} / \mathrm{min}$. In separate experiments, 5 $\mu \mathrm{M}$ nifedipine was also added to the Tyrode solution. After acquisition of a stable baseline, the perfusate was switched for $3 \mathrm{~min}$ to a $20 \mathrm{~mm} \mathrm{~K}^{+}$ solution containing the appropriate channel blockers. Complete solution exchanges occurred within $10 \mathrm{sec}$.

To determine which cells were transfected with the DHP-LTC or DHP-LTCnoPDZ, neurons were cotransfected with EGFP (5:1 ratio of channel to EGFP). Similar to the findings reported by Dolmetsch et al. (2001), under these conditions, $>90 \%$ of the neurons positive for EGFP also exhibited Xpress-tagged calcium channels $(n>50)$. For neurons transfected with dihydropyridine-insensitive L-type calcium channels, recording solutions contained TTX, AP5 and nifedipine. To determine the contribution of DHP-LTCs and DHP-LTCnoPDZs to the overall increase in $\left[\mathrm{Ca}^{2+}\right]_{\mathrm{i}}$ after $20 \mathrm{~mm} \mathrm{~K}^{+}$depolarization, diltiazem $(100 \mu \mathrm{M})$ was added to the recording solutions in a subset of experiments $(n=8)$. Differences in the residual increase in $\left[\mathrm{Ca}^{2+}\right]_{\mathrm{i}}$ after diltiazem exposure was not significantly different between groups ( $0.4 \mathrm{~nm} ; p>0.05)$. After completion of each experiment, background light levels were determined. Records were later corrected for background and converted to $\left[\mathrm{Ca}^{2+}\right]_{\mathrm{i}}$ by the equation $\left[\mathrm{Ca}^{2+}\right]_{\mathrm{i}}=K_{\mathrm{d}} \beta\left(R-R_{\min }\right) /\left(R_{\max }-R\right)$, in which $R$ is the $405 / 490 \mathrm{~nm}$ fluorescence ratio. The dissociation constant $\left(K_{\mathrm{d}}\right)$ used for Indo-1 was $250 \mathrm{~nm} . R_{\min }, R_{\max }$, and $\beta$ were determined in ionomycin-permeabilized cells in calcium-free ( 1 mM EGTA) and $5 \mathrm{~mm}$ $\mathrm{Ca}^{2+}$ buffers. Values of $R_{\min }, R_{\max }$, and $\beta$ were $0.19,2.3$, and 3.5, respectively.

\section{Results}

Interactions between EGFP-VSNL and PDZ domain proteins

Previous reports have shown that $\alpha_{1 \mathrm{C}}$ is expressed in a punctate pattern, heavily concentrated in the cell soma and proximal dendrites of neurons (Westenbroek et al., 1990; Hell et al., 1993). Using immunocytochemistry and confocal microscopy techniques, we found that expression of EGFP alone did not affect the normal distribution of $\alpha_{1 \mathrm{C}}$ (Fig. $1 A$ ). Three-dimensional reconstructions of immunolabeled neurons indicated that the vast majority of $\alpha_{1 \mathrm{C}}$ expression was localized to the membrane surface. We hypothesized that the clustering of L-type calcium channels was based on $\alpha_{1 \mathrm{C}}$ binding to PDZ domain proteins. Because the last four amino acids of $\alpha_{1 \mathrm{C}}$ are believed to promote its interaction with PDZ domain proteins, we overexpressed EGFP-VSNL in an attempt to out-compete endogenous $\alpha_{1 \mathrm{C}}$ protein for PDZ binding sites. In neurons transfected with EGFP-VSNL, the distribution of endogenous $\alpha_{1 \mathrm{C}}$ was markedly altered (Fig. $1 B$ ). The number of intense clusters of fluorescence generated by immunolabeled $\alpha_{1 \mathrm{C}}$ was significantly decreased (Fig. $\left.1 D\right)(n=\sim 15$ per group; $p<0.001)$. Furthermore, the $\alpha_{1 \mathrm{C}}$ immunofluorescence in EGFP-VSNL-expressing neurons was reminiscent of the staining observed in glial cells (Fig. $1 \mathrm{~B}$, arrowheads) (Agrawal et al., 2000; Chung et al., 2001; Latour et al., 2001).

Although EGFP was uniformly distributed throughout the cell, expression of EGFP-VSNL fluorescence was concentrated into puncta within the cell soma and dendrites (Fig. $1 A, B$ ). This expression pattern was similar to the localization of $\alpha_{1 \mathrm{C}}$ protein under control conditions, suggesting that EGFP-VSNL competed with $\alpha_{1 \mathrm{C}}$ for localization at PDZ binding sites. In keeping with this idea, the number of EGFP-VSNL puncta, when added to the number of residual $\alpha_{1 \mathrm{C}}$ aggregations, was not significantly different $(p>0.05)$ from the total number of fluorescent $\alpha_{1 C}$ clusters observed under control conditions (Fig. 1D). The punctate distribution of EGFP-VSNL peaked $\sim 10-15 \mathrm{hr}$ after transfection, becoming more difficult to resolve at $24 \mathrm{hr}$ (see Fig. $4 \mathrm{C}$ ), consistent with the idea that the PDZ binding sites normally taken up by L-type calcium channels were being fully occupied by EGFP-VSNL.

To verify that mislocalization of $\alpha_{1 C}$ by EGFP-VSNL was specifically dependent on the VSNL sequence, EGFP was tethered to ITTL. ITTL are the last four amino acids of one splice variant of the calcium channel $\alpha_{1 \mathrm{D}}\left(\mathrm{Ca}_{\mathrm{V}} 1.3\right)$ subunit (Ihara et al., 1995; Safa et al., 2001) and were not predicted to interact with PDZ binding domains. As with EGFP, EGFP-ITTL exhibited a homogenous distribution throughout the cell, without altering $\alpha_{1 \mathrm{C}}$ labeling (Fig. 1C,D). Because most of the L-type calcium channels in brain are composed of either an $\alpha_{1 \mathrm{C}}$ or an $\alpha_{1 \mathrm{D}}$ subunit, the data suggest that these two populations of L-type calcium channels likely have different intracellular distributions and thus may 

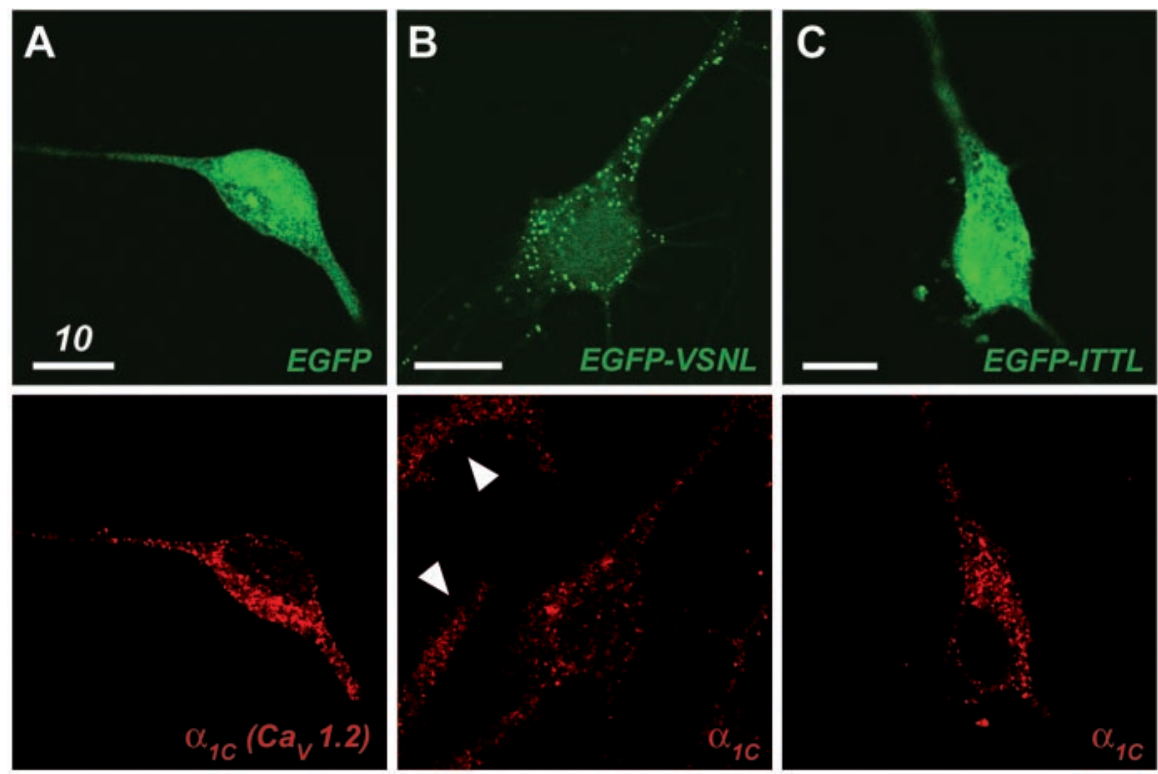

D

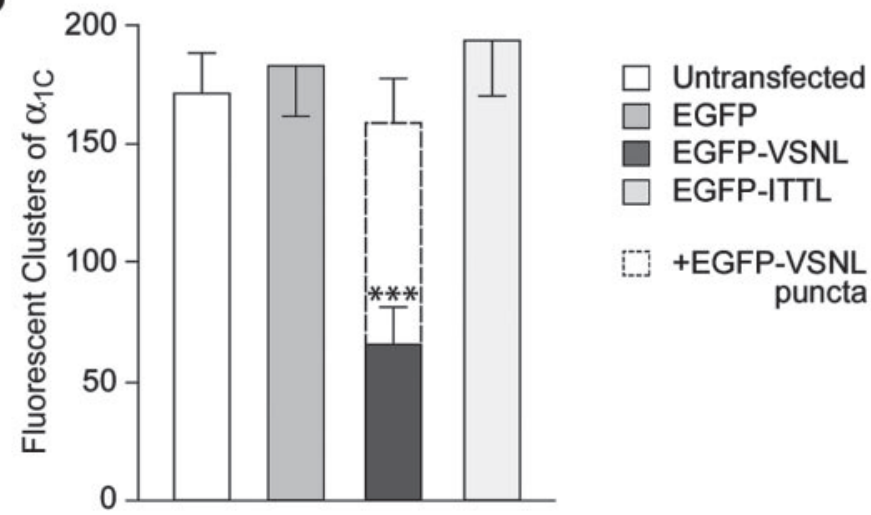

Figure 1. Disruption of endogenous $\alpha_{1 C}$ clustering in neurons transfected with EGFP-VSNL. A, Paired confocal images of a neuron transfected with EGFP (green) and stained using an antibody for the calcium channel $\alpha_{1 c}$ subunit (red). The distribution of endogenous $\alpha_{1 C}$ protein in EGFP-transfected neurons was indistinguishable from untransfected neurons (data not shown). $B$, EGFP-VSNL exhibited a punctate expression pattern similar to the distribution of $\alpha_{1 c}$ in control cells. In neurons transfected with EGFP-VSNL, $\alpha_{1}$ labeling tended to be more diffuse, similar to staining in glial cells (arrowheads). C, EGFP-ITTL exhibited uniform fluorescence similar to EGFP, with no effect on $\alpha_{1}$ localization. D, EGFP-VSNL expression resulted in a significant $(p<0.001)$ reduction in the fluorescent clustering of $\alpha_{1 c}$. The number of EGFP-VSNL puncta, when added to the number of residual $\alpha_{1 c}$ aggregations, was not significantly different $(p>0.05)$ from the total number of fluorescent clusters of $\alpha_{1 c}$ observed in control conditions.

interact with distinct second messenger systems (see Discussion).

Because the last four amino acids of receptors and ion channels promote specific interactions with particular PDZ domain proteins, and VSNL expression appeared to alter the subcellular distribution of endogenous $\alpha_{1 \mathrm{C}}$ protein, we wanted to verify that EGFP-VSNL did indeed interact with PDZ domain proteins. To test this, COS-7 cells were transfected with cDNA encoding for NIL-16 (a PDZ domain protein hypothesized to interact with $\left.\alpha_{1 \mathrm{C}}\right)$ and either EGFP or EGFP-VSNL. In control experiments, EGFP expression was diffuse within the cytosol and nucleus (Fig. $2 A)$ and did not accumulate at the plasma membrane with NIL-16 (Fig. 2B,C). Interestingly, when EGFP-VSNL was expressed without NIL-16, its cellular distribution was similar to EGFP (Fig. 2D, bottom cell). However, when coexpressed with NIL-16, EGFP-VSNL was also observed as aggregations at the plasma membrane (Fig. 2D, top cell), colocalizing with NIL-16
(Fig. 2E,F). Coimmunoprecipitation experiments verified the interaction between EGFP-VSNL and NIL-16 (Fig. 2G, lane 6). The interaction between these two proteins was dependent on VSNL, because EGFP did not coimmunoprecipitate with NIL-16 in control experiments (Fig. $2 G$, lane 3 ).

To verify that the alteration in neuronal $\alpha_{1 \mathrm{C}}$ immunolabeling after EGFPVSNL expression was not caused by a change in protein expression, L-type calcium channel currents were isolated using patch-clamp methods. Application of the L-type calcium channel blocker nifedipine $(5 \mu \mathrm{M})$ resulted in a $34.1 \pm 2.6 \%$ (mean \pm SEM) reduction of the wholecell calcium current in EGFP-VSNLexpressing neurons $(n=14)$. This percentage of L-type current was not significantly different from untransfected (35.6 $\pm 2.9 \% ; n=14)$ or EGFP transfected $(37.8 \pm 3.2 \% ; n=11)$ neurons (Fig. 3). Furthermore, whole-cell calcium current densities remained unchanged, eliminating the possibility that EGFPVSNL produced a general decrease in calcium channel expression (not transfected: $7.79 \pm 0.98 \mathrm{pA} / \mathrm{pF}$; EGFP: $9.62 \pm 1.60$ pA/pF; EGFP-VSNL: $9.32 \pm 1.12 \mathrm{pA} / \mathrm{pF}$ ).

Although the above data demonstrate that the quantity of L-type calcium current remained unchanged in EGFPVSNL-expressing neurons, we considered the possibility that the retention of current was caused by the replacement of $\alpha_{1 \mathrm{C}}$ subunits with $\alpha_{1 \mathrm{D}}$. Because L-type calcium channels composed of $\alpha_{1 \mathrm{C}}$ are more sensitive to DHP than those containing $\alpha_{1 \mathrm{D}}$ (Xu and Lipscombe, 2001), the dose dependence of nifedipine block was determined. For each concentration of nifedipine examined ( $1 \mathrm{nM}$ Tо $10 \mu \mathrm{M}$ ), block of L-type calcium current in EGFPVSNL-expressing neurons $(n=7)$ did not differ significantly from control $(n=9)$

(supplemental Fig. 1; available at www.jneurosci.org). Furthermore, in both groups, a high-affinity $(\sim 30 \mathrm{~nm})$ and low-affinity $(\sim 1 \mu \mathrm{M})$ DHP binding site was found, consistent with previous reports regarding the concentrations required to block $\alpha_{1 \mathrm{C}}$ and $\alpha_{1 \mathrm{D}}$ L-type calcium channels.

\section{Global calcium dynamics remain unchanged after EGFP-VSNL expression}

The next series of experiments determined that EGFP-VSNL did not affect global calcium influx. Neurons transfected with either EGFP or EGFP-VSNL were loaded with the calcium indicator Indo-1. Somatic calcium concentrations were measured during a $20 \mathrm{mM} \mathrm{K}^{+}(+25 \mu \mathrm{M} \mathrm{AP5})$ stimulus protocol that mimicked the conditions used to activate CREB via calcium entry through L-type calcium channels (see below). Intracellular calcium concentrations in EGFP-VSNL-transfected neurons $(n=7)$ increased by $106.2 \pm 20.5 \mathrm{nM}$, from a basal concentration of $46.7 \pm$ 
$6.0 \mathrm{nM}$, which was not significantly different from their EGFP-transfected $(n=8)$ counterparts $(110.3 \pm 10.3 \mathrm{~nm}, 46.4 \pm 4.4$ nM) (Fig. $4 A, B$ ). Furthermore, in the presence of $5 \mu \mathrm{M}$ nifedipine, intracellular calcium concentrations increased by $40.2 \pm$ $3.8 \mathrm{nM}$ in EGFP-VSNL-transfected ( $n=$ 9) and $39.4 \pm 5.6 \mathrm{nM}$ in EGFP-transfected $(n=8)$ neurons (Fig. 4C,D). The approximate $60 \%$ block by nifedipine after 20 $\mathrm{mM} \mathrm{K}^{+}$depolarization was consistent with previous biophysical and imaging work suggesting that L-type calcium channels activate at more negative potentials than other voltage-gated calcium channels (Mermelstein et al., 2000, 2001).

EGFP-VSNL specifically disrupts L-type calcium channels from signaling to CREB

The effect of EGFP-VSNL on CREB activation was determined using a phosphoSer ${ }^{133}$-specific CREB antibody (Ginty et al., 1993) with nuclear immunofluorescence quantified from confocal sections. To activate CREB via calcium entry through L-type calcium channels, neurons were depolarized for $3 \mathrm{~min}$ with 20 $\mathrm{mM} \mathrm{K}^{+}$(Mermelstein et al., 2001). To eliminate NMDA receptor-mediated CREB phosphorylation, AP5 was applied both $30 \mathrm{~min}$ before and during depolarization. In neurons expressing EGFP, 20 $\mathrm{mM} \mathrm{K}{ }^{+}$produced a significant increase $(p<0.001)$ in CREB phosphorylation, equal to the effect observed in neighboring untransfected cells (Fig. 5A). The 20 $\mathrm{mM} \mathrm{K}^{+}$-induced increase in CREB phosphorylation was blocked by both nifedipine and KN-93 $(2 \mu \mathrm{M})(p<0.001)$ but not by the control drug KN-92 $(10 \mu \mathrm{M})$ (Fig. $5 B$ ), demonstrating that under mild stimulation conditions, L-type channels mediate CREB phosphorylation via activation of a CaM-dependent protein kinase (Bito et al., 1996; Wu et al., 2001).

Although EGFP-transfected neurons exhibited a stimulation-induced increase in CREB phosphorylation identical to untransfected neurons, CREB phosphorylation was significantly reduced $(p<0.001)$ in neurons expressing EGFP-VSNL (Fig. $5 C, D)$. The reduction in CREB phosphorylation occurred although the amount of calcium entering the cell through L-type calcium channels remained the same (Fig. 4). Intriguingly, the reduction in CREB phosphorylation by EGFP-VSNL was observed only with stimulation parameters designed to activate CREB specifically via calcium entry through L-type channels. EGFP-VSNL-transfected neurons treated for 3 min with NMDA $(50 \mu \mathrm{M})$ in the presence of nifedipine did not exhibit decreased levels of CREB phosphorylation (Fig. 5D). Under these condi-

G EGFP-VSNL.
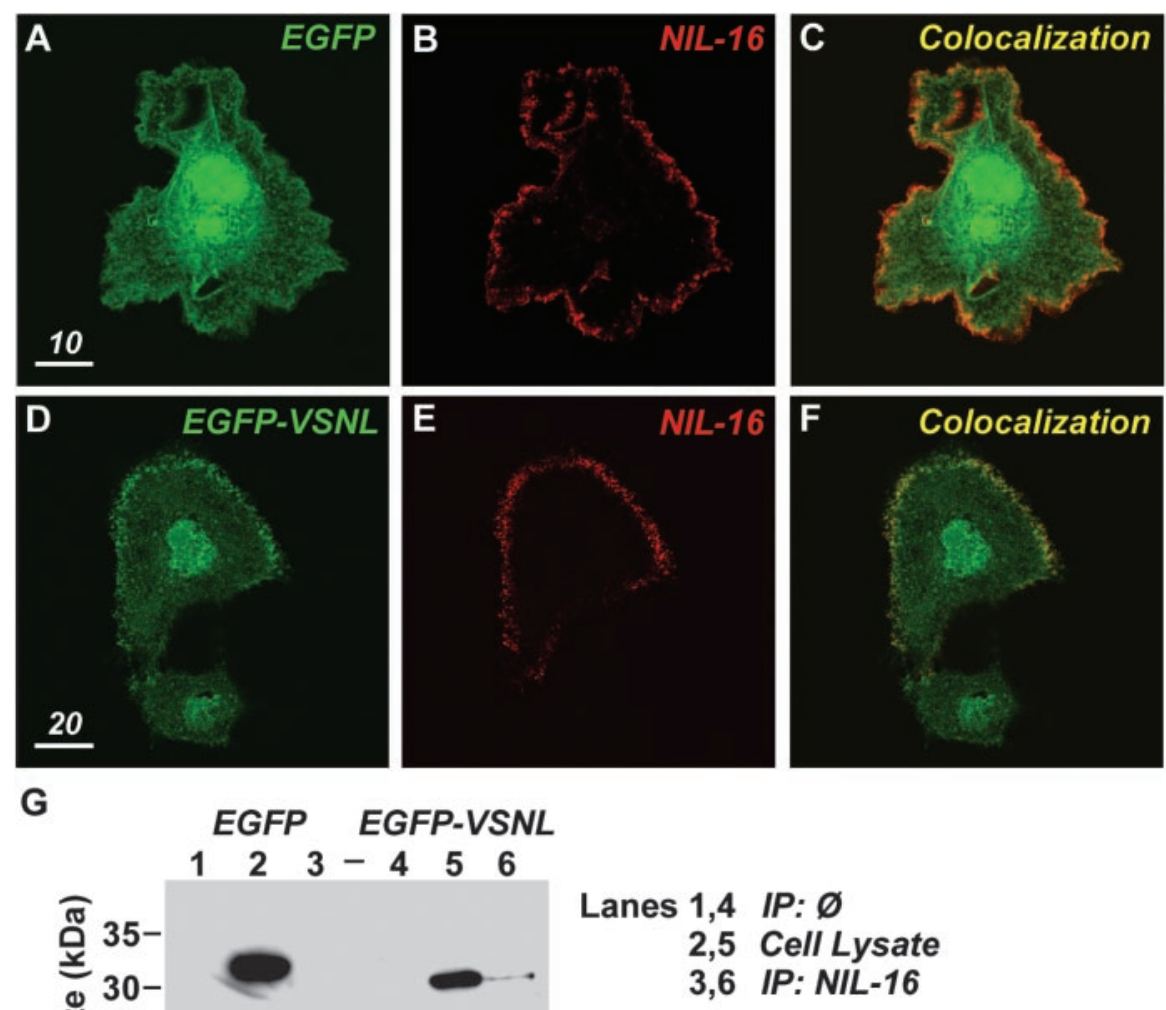

Probe: EGFP

Figure 2. EGFP-VSNL interacts with the PDZ domain protein NIL-16. A-C, Confocal image of a COS cell expressing EGFP (green) and NIL-16 (red). The two proteins do not appreciably colocalize. D, Two cells transfected with EGFP-VSNL. E, The top cell also expressed NIL-16. F, By colocalizing with the fluorophore, NIL-16 promoted EGFP-VSNL expression at the plasma membrane (yellow). G, EGFP-VSNL (lane 6), but not EGFP (lane 3), coimmunoprecipitated with NIL-16, demonstrating that the interaction between the two proteins is dependent on the PDZ interaction sequence. EGFP and EGFP-VSNL are not detected when the antibody for NIL-16 is omitted from the immunoprecipitation step (lanes 1, 4). Direct probing of the cell lysate indicated comparable concentrations of EGFP and EGFP-VSNL protein (lanes 2,5).
A

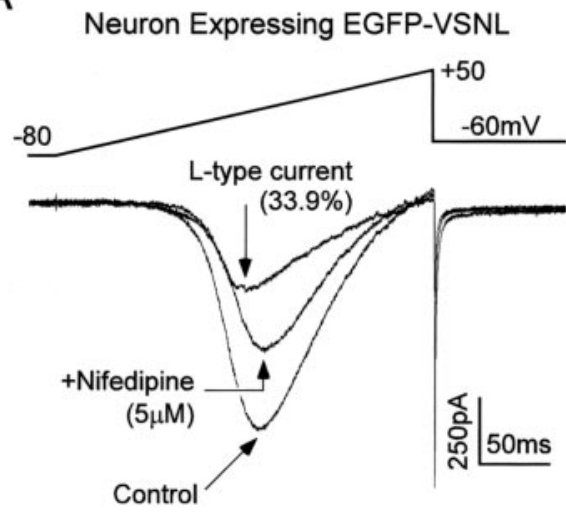

B

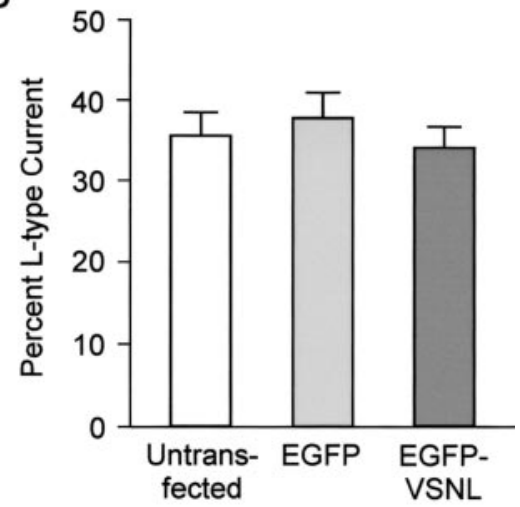

Figure 3. EGFP-VSNL did not alter L-type calcium channel expression. A, A representative whole-cell patch-clamp recording taken from a neuron transfected with EGFP-VSNL ( $5 \mathrm{~mm} \mathrm{Ba}^{2+}$ was used as the charge carrier). Application of nifedipine (5 $\left.\mu \mathrm{M}\right)$ isolated the L-type current. The voltage waveform is shown above the current traces. $B$, The L-type calcium channel component of the whole-cell current was not significantly different between untransfected neurons and those transfected with either EGFP or

tions, AP5 completely blocked stimulus-induced CREB phosphorylation, indicating an NMDA receptor-mediated event (data not shown). Furthermore, similar to L-type calcium channels, a significant component of CREB phosphorylation after brief NMDA receptor stimulation is dependent on activation of CaM- 

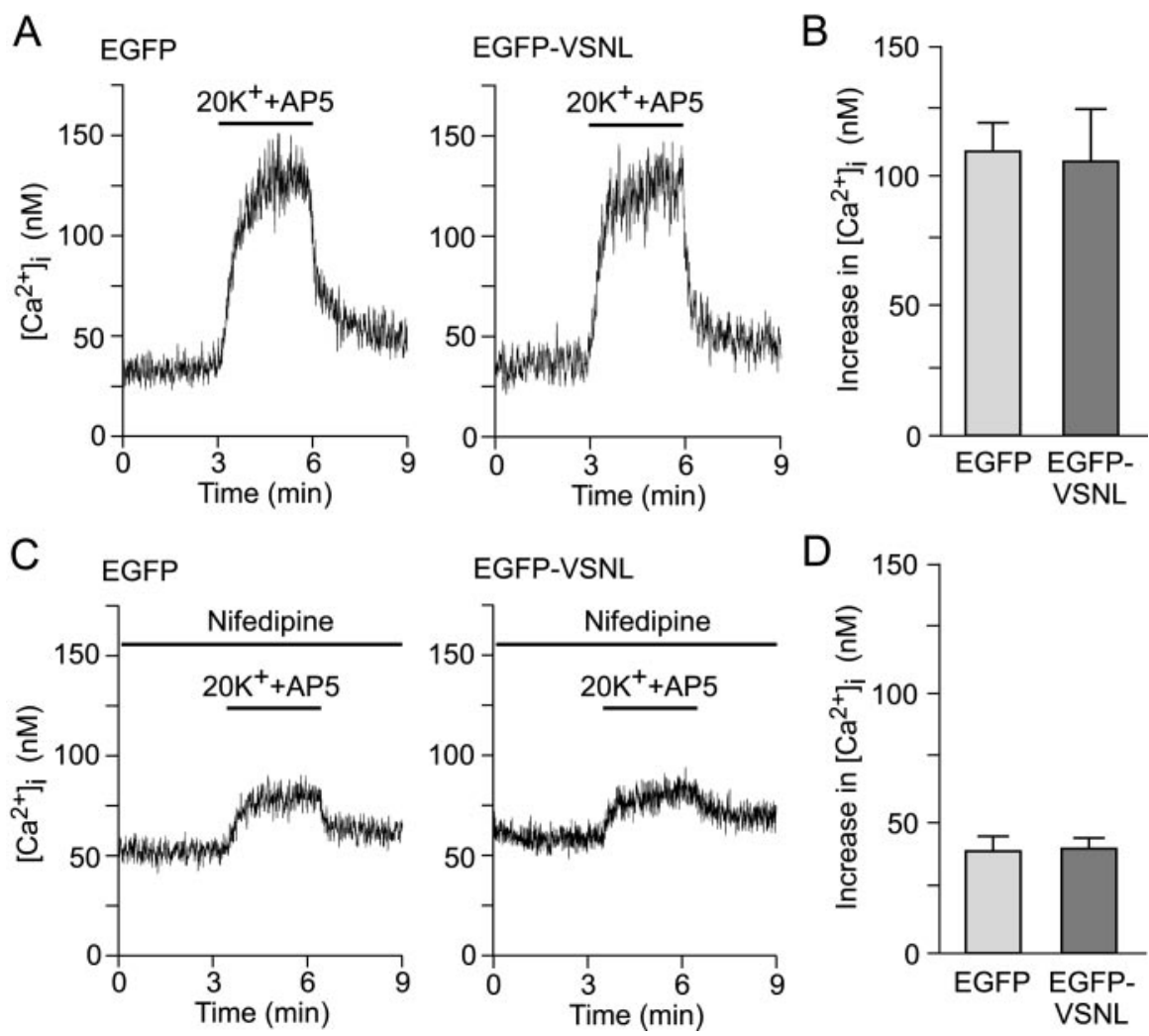

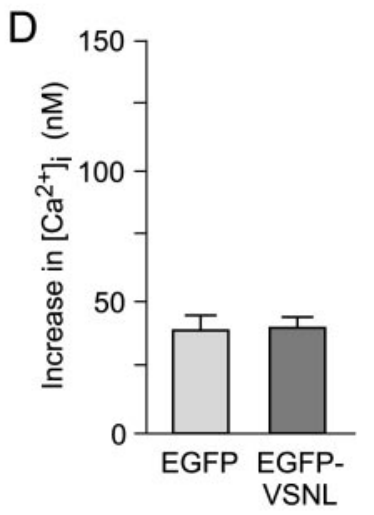

Figure 4. EGFP-VSNL does not affect global calcium signaling. $A$, Representative recordings of $\left[\mathrm{Ca}^{2+}\right]_{\mathrm{i}}$ measurements during application of $20 \mathrm{mmK}^{+}$in EGFP-and EGFP-VSNL-expressing neurons. AP5 $(25 \mu \mathrm{m})$ was present throughout the recording to block NMDA receptors. $B$, The stimulus-induced increase in somatic calcium concentrations did not differ between groups. C, D, Similar calcium photometry experiments in the presence of nifedipine. The rise in somatic intracellular calcium attributable to L-type and non-L-type calcium channels after depolarization is not different between EGFP- and EGFP-VSNL-expressing neurons.

dependent protein kinases (Bito et al., 1996; Wu et al., 2001; Impey et al., 2002). Consistent with this finding, KN-93 significantly decreased CREB phosphorylation after depolarization in the presence of nifedipine (supplemental Fig. 2; available at www. jneurosci.org). The effect of KN-93 was identical in both untransfected and EGFP-VSNL-transfected neurons, demonstrating that the influence of EGFP-VSNL on L-type calcium channelmediated CREB signaling could not be attributed to a nonspecific effect on calcium, CaM, or CaM-dependent protein kinases.

We next sought to determine whether expression of EGFP-VSNL would impact CREB-dependent gene expression. In addition to either EGFP or EGFP-VSNL, neurons were transfected with a luciferase-based reporter of CRE-dependent transcription. A 3 min $20 \mathrm{~mm} \mathrm{~K}^{+}$stimulus (+AP5) significantly ( $p<$ $0.05)$ increased CRE-dependent transcription $[22,370 \pm 9416$ reflective light units (RLU)] in EGFP-transfected neurons $(n=9)$ in comparison with unstimulated cells $(n=10)$. Conversely, the increase in CRE-dependent transcription observed in EGFPVSNL-transfected neurons ( $3213 \pm 1697 \mathrm{RLU} ; n=9$ ) was not significantly different from their unstimulated controls $(n=10)$ (Fig. 6A). Furthermore, when transfected with a constitutively active reporter, expression between groups was not significantly different (EGFP: 599,875 \pm 59,744 RLU; EGFP-VSNL: $529,254 \pm 25,171 \mathrm{RLU} ; n=10$ per group), eliminating the possibility that the reduction in CRE-dependent transcription observed in EGFP-VSNL transfected neurons was caused by a nonspecific decrease in gene expression.

$\mathrm{K}^{+}(90 \mathrm{~mm})$ has also been used as a stimulus to activate L-type calcium channel-mediated gene expression (Bito et al., 1996).
This stimulus will activate not only CREB, but other transcription factors as well, including NFATc4 (Graef et al., 1999). For $\mathrm{CREB}$, the stronger depolarization results in increased calcium entry through L-type channels and greater CREB activation. Thus we tested whether expression of EGFP-VSNLwould again result in a diminution of CREB signaling. In EGFP-transfected neurons $(n=4), 90$ $\mathrm{mM} \mathrm{K}^{+}$(+AP5) increased CRE-luciferase expression by $56,842 \pm 18,978$ RLU relative to unstimulated controls $(n=4)$. In contrast, EGFP-VSNL neurons $(n=5)$ exhibited an increase of only $6346 \pm 1222$ RLU when compared with unstimulated EGFP-VSNL neurons $(n=5)$. CRE-dependent transcription triggered by the brief stimulus was significantly less $(p<0.02)$ in EGFP-VSNL neurons. Consistent with the idea that attenuation of CRE-dependent transcription is through inhibition of CREB phosphorylation, EGFP-VSNL-expressing neurons also exhibited a significant $(p<$ 0.05 ) decrease in $90 \mathrm{mM} \mathrm{K}^{+}$-induced CREB phosphorylation (data not shown).

Because NFAT-dependent transcription has been shown to rely on calcium entry through L-type channels after a 90 $\mathrm{mM} \mathrm{K}^{+}$depolarization, we tested whether displacement of $\alpha_{1 \mathrm{C}}$ L-type channels would also affect the activation of this transcription factor. Neurons were transfected with EGFP or EGFP-VSNL, along with a luciferase-based reporter of NFAT transcription. After a 3 $\min 90 \mathrm{~mm} \mathrm{~K}^{+}$stimulus, EGFP-VSNL-transfected neurons $(n=$ 10) exhibited an increase of $7217 \pm 2409$ RLU in comparison with unstimulated controls $(n=10)$, which was not significantly different from the stimulus-induced effect in EGFP neurons (8459 $\pm 1742 \mathrm{RLU} ; n=10$ per group) (Fig. 6 B). AP5 was omitted from these experiments because NMDA receptors do not directly activate NFAT-dependent transcription under these conditions (Graef et al., 1999). In another test, nifedipine was used to block NFAT-dependent transcription mediated by endogenous synaptic activity. Again, EGFP-VSNL failed to block L-type channelmediated NFAT-dependent transcription (EGFP: 21,437 \pm 3982 ; EGFP-VSNL: $21,426 \pm 2429 \mathrm{RLU} ; n=10$ per group), suggesting that a mechanism independent of $\alpha_{1 \mathrm{C}}$ localization is responsible for L-type channel regulation of NFAT activity (see Discussion).

$\alpha_{1 C}$ subunits lacking the PDZ interaction sequence exhibit a significant impairment in the ability to signal to CREB

Recently, Dolmetsch et al. (2001) constructed an epitope-tagged $\alpha_{1 \mathrm{C}}$ subunit containing a threonine to tyrosine point mutation at position 1039, resulting in the generation of a DHP-insensitive L-type calcium channel (DHP-LTC). Depolarizations in the presence of DHPs isolate CREB phosphorylation and CREdependent transcription arising from calcium entry specifically through these channels. Furthermore, DHP-LTCs are still sensitive to diltiazem $(100 \mu \mathrm{M})$, a non-DHP blocker of L-type calcium channels. As such, we used this construct to examine the role of the PDZ interaction sequence on L-type calcium channel CREB responses. 
Hippocampal neurons were transfected with DNA encoding for either the full-length DHP-LTC or a truncated version in which the PDZ interaction sequence was absent because of the insertion of a premature stop codon (DHPLTCnoPDZ). Both constructs localized predominantly to the soma and proximal dendrites of neurons (Fig. $7 B, C$ ), suggesting that removal of the terminal five amino acids did not have a dramatic effect on insertion of the subunit into the plasma membrane (see Discussion). Furthermore, after a 3 min stimulation with $20 \mathrm{mM} \mathrm{K}^{+}$(+AP5 and nifedipine), increases in intracellular calcium attributable to both channels were not significantly different (DHP-LTC: $40.9 \pm 6.4$ nM, $n=7$; DHP-LTCnoPDZ: $50.1 \pm 5.4$ nM, $n=6$ ) (Fig. 7A). Under these same stimulation conditions, neurons expressing DHP-LTCs exhibited a significant increase in CREB phosphorylation that could be blocked by diltiazem (Fig. 7B). Conversely, neurons transfected with DHP-LTCnoPDZ did not exhibit the same stimulus-induced increase in CREB phosphorylation (Fig. 7C).

In the final experiment, neurons were transfected with the CRE-luciferase reporter and either DHP-LTC or DHPLTCnoPDZ. As reported originally by Dolmetsch et al. (2001), whereas DHPLTCs are capable of activating CREB, they are not as proficient as endogenous L-type calcium channels. Thus, we were not surprised to find that neurons expressing DHP-LTCs did not consistently exhibit increases in luciferase expression after a $3 \mathrm{~min} 20 \mathrm{mM} \mathrm{K}^{+}$stimulus (in the presence of AP5 and nifedipine). Consequently, neurons were stimulated with 20 $\mathrm{mM} \mathrm{K}^{+}$(+AP5 and nifedipine) for $3 \mathrm{hr}$ in the presence or absence of diltiazem (Fig. 7D). Under these conditions, DHP-LTCs generated an increase in luciferase activity by $102,569 \pm 9,899 \mathrm{RLU}$ ( $n=10$ per group), significantly greater than CRE-dependent transcription attributable to DHP-LTCnoPDZs (42,752 \pm 9077 RLU; $n=10$ per group). Intriguingly, the results suggest that although DHP-LTCnoPDZs are capable of activating CREB, they are less efficient than those channels containing the PDZ interaction sequence (see Discussion).

\section{Discussion}

The subcellular localization of $\alpha_{1 \mathrm{C}}$-comprised L-type calcium channels appears critical for CREB-dependent gene expression. EGFPVSNL, which can interact with the PDZ domain protein NIL-16, reduced L-type calcium channel aggregations when expressed in neurons. After expression of EGFP-VSNL, CREB phosphorylation and CRE-dependent transcription mediated by calcium entry through L-type calcium channels was significantly attenuated, although increases in somatic calcium concentrations after stimulation remained unchanged. Furthermore, the ability of L-type cal-
B

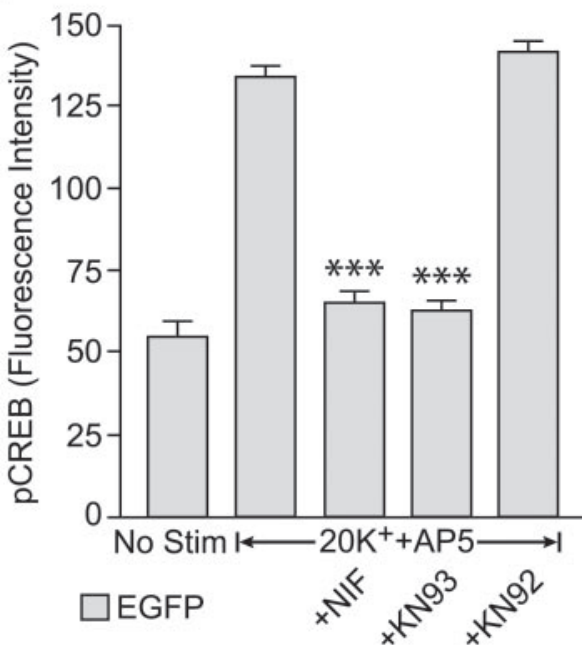

Figure 5. EGFP-VSNL specifically attenuated L-type calcium channel-mediated CREB phosphorylation. $A$, Immunolabeling studies demonstrated that expression of EGFP did not alter $20 \mathrm{~mm} \mathrm{~K}^{+}-(+\mathrm{AP5})$ induced CREB phosphorylation. $B$, Nifedipine and $\mathrm{K}^{+}$. The negative control KN-92 $(10 \mu \mathrm{m})$ had no effect. C, D, Expression of EGFP-VSNL significantly $(p<0.001)$ attenuated L-type

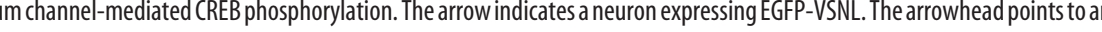
(a) EF-VSNL attenuation of CREB phosphorylation was observed following parameters designed to activate L-type calcium channels (i.e., $20 \mathrm{~mm} \mathrm{~K}^{+}+$AP5). Conversely, NMDA receptor-

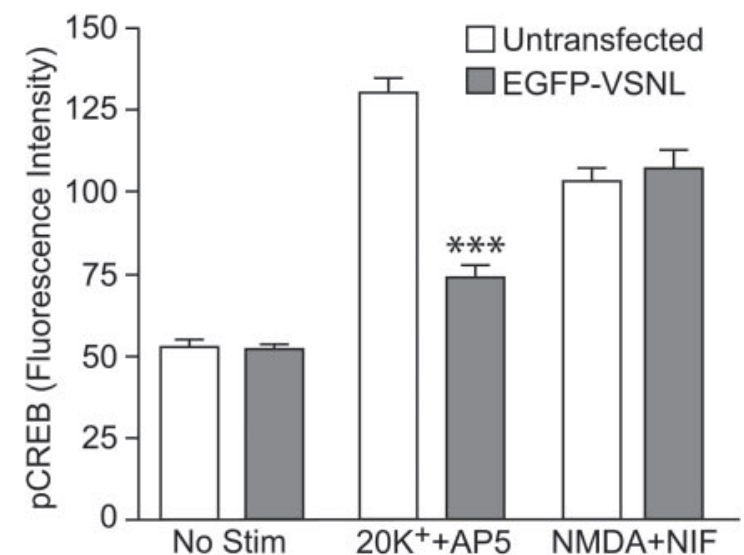


A

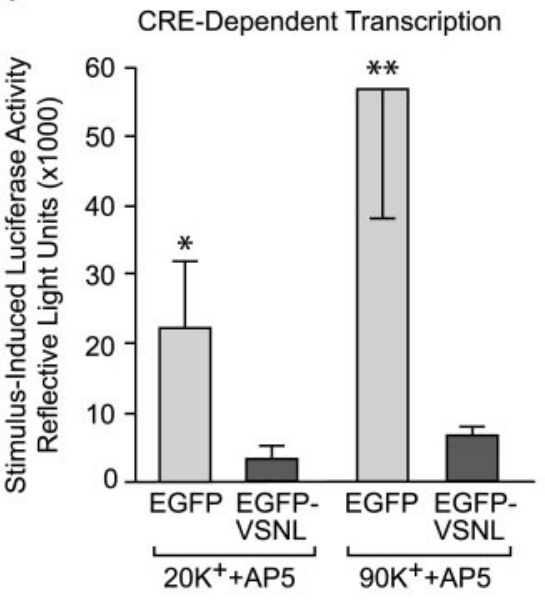

B

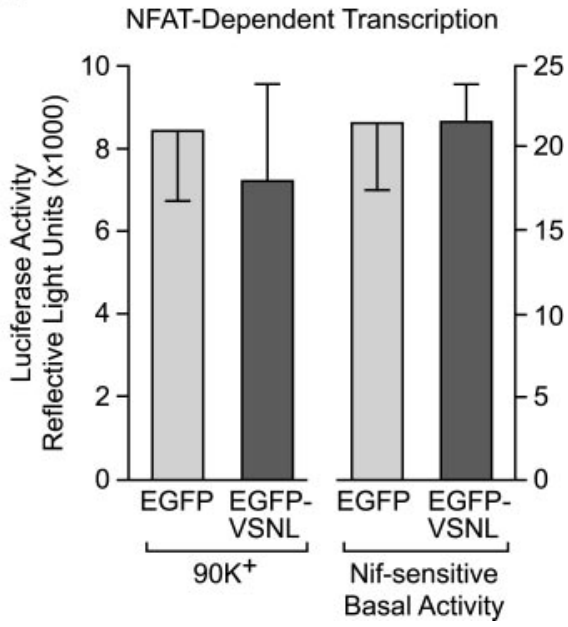

Figure 6. EGFP-VSNL inhibited CRE-dependent transcription, whereas NFAT-dependent transcription was unaffected. $A$, A 3 $\min 20 \mathrm{~mm} \mathrm{~K}^{+}$stimulus activated CRE-dependent transcription in EGFP $(p<0.05)$ but not in EGFP-VSNL-expressing neurons. Transcription was measured using a luciferase-based reporter construct. Similarly, after a 3 min depolarization with $90 \mathrm{~mm} \mathrm{~K}^{+}$, CRE-dependent transcription in EGFP-VSNL-transfected neurons was significantly attenuated $(p<0.02)$. AP5 was used to block NMDA receptors. B, After a $90 \mathrm{~mm} \mathrm{~K}^{+}$stimulus, NFAT-dependent transcription was unaltered by EGFP-VSNL expression. The L-type calcium channel component of NFAT-dependent transcription triggered by endogenous synaptic activity was also unaffected by EGFP-VSNL.

ferent classes of voltage-gated calcium channels support unique cellular functions, the utilization of linking proteins is not surprising. In fact, compartmentalization of calcium channels may be a common theme, because recent data have shown that the N-type calcium channel subunit $\alpha_{1 \mathrm{~B}-1}\left(\mathrm{Ca}_{\mathrm{V}} 2.2 \mathrm{a}\right)$ contains targeting sequences to promote its interaction with the adaptor proteins Mint/x11-like protein 1 (Mint1) and calcium/calmodulin-dependent serine protein kinase (CASK) (Maximov et al., 1999; Kaneko et al., 2002; Maximov and Bezprozvanny, 2002). The resulting interactions target $\mathrm{N}$-type calcium channels to the presynaptic terminal where they play a critical role in neurotransmitter release.

By manipulating various regions of the $\alpha_{1 \mathrm{C}}$ subunit, a clearer understanding of how L-type calcium channels are preferentially linked to CREB and CRE-dependent transcription is emerging. Dolmetsch et al. (2001) found that removal of the CaM-binding "IQ motif" from $\alpha_{1 \mathrm{c}}$ produces L-type calcium channels incapable of signaling to CREB, demonstrating an inherent prerequisite within the channel for activation of CRE-dependent transcription. Yet various calcium channel $\alpha_{1}$ subunits, not just $\alpha_{1 \mathrm{C}}$, contain similar (or identical) IQ motifs and interact with CaM (Lee et al., 1999; Peterson et al., 1999). Thus, another mechanism must provide L-type calcium channels with a "private line" to the nucleus, allowing only these voltage-gated calcium channels to trigger CREB phosphorylation. We believe that this second requirement is fulfilled by interactions between $\alpha_{1 \mathrm{C}}$ and PDZ domain proteins. Anchoring $\alpha_{1 \mathrm{C}}$ to regions where CREB signaling is initiated would not only promote the ability of these particular L-type calcium channels to activate gene expression but also help to exclude other calcium channels from localizing to these same regions and thus signaling themselves.

The studies with DHP-LTC and DHP-LTCnoPDZ provide support for this hypothesis. After a brief and mild stimulation (3 min with $20 \mathrm{mM} \mathrm{K}^{+}$), activation of DHP-LTCs, but not DHPLTCnoPDZs, results in the phosphorylation of CREB (Fig. 7). Interestingly, with longer stimulation conditions (e.g., $3 \mathrm{hr}$ ), L-type calcium channels lacking the PDZ interaction sequence can partially overcome their disadvantage in signaling to CREB, perhaps by overwhelming endogenous calcium buffering. Consistent with this idea, after a prolonged and robust depolarization (resulting in micromolar increases in intracellular calcium), DHP-LTCs containing the IQ motif but lacking the final 502 amino acids from its $\mathrm{C}$ terminus (including VSNL) exhibit CREB phosphorylation and CREdependent transcription to a lesser extent than the full-length channel (Dolmetsch et al., 2001).

In our experiments, we used two distinct strategies in examining the importance of the $\alpha_{1 \mathrm{C}}$ PDZ interaction sequence on L-type calcium channel-mediated CREB responses. With EGFP-VSNL, we took a freely diffusible protein (EGFP) and promoted its targeting to the membrane surface (Fig. $1 B)$. As a result, $10-15 \mathrm{hr}$ after transfection, a clear difference in the distribution between EGFP and EGFP-VSNL was observed. At later time points (Fig. 5C), differences between the two fluorophores became more difficult to resolve. We attribute this phenomenon to EGFP-VSNL saturation of the PDZ protein binding sites, with excess EGFP-VSNL distributed similarly to EGFP. When comparing the localization of DHP-LTC with DHP-LTCnoPDZ, no striking differences were observed. Both proteins contain 24 transmembranespanning regions and the intracellular domains that promote interactions with the calcium channel accessory subunits necessary for channel insertion into the plasma membrane. As such, both DHPLTC and DHP-LTCnoPDZ were targeted to the cell soma and dendrites (Fig. 7 B, C). Presumably, at the subcellular level, differences in their localization exist.

Currently, only two PDZ domain proteins are known to interact with VSNL: CIPP and NIL-16 (Kurschner et al., 1998; Kurschner and Yuzaki, 1999). CIPP is expressed within the cerebellum; NIL-16 is expressed within the cerebellum and hippocampus. Thus, our working hypothesis is that in hippocampal neurons, interactions between L-type calcium channels and NIL-16 are necessary for efficient signaling to CREB. However, coimmunoprecipitation experiments examining potential interactions between $\alpha_{1 \mathrm{C}}$ and NIL-16 in neurons have thus far been unsuccessful (Kurschner and Yuzaki, 1999; J. P. Weick and P. G. Mermelstein, unpublished observations). This is most likely attributable to various factors, including the relative low abundance of NIL-16 in neurons and the poor sensitivity of the NIL-16 antibody (Kurschner and Yuzaki, 1999). Future experiments will need to overcome these technical limitations to definitively reveal which PDZ domain protein(s) interacts with L-type calcium channels.

Future research will also need to identify other proteins localized to these signaling complexes. Because of its multiple roles in L-type calcium channel function, CaM may be concentrated within these subcellular regions. Interactions between $\alpha_{1 C^{-}}$ comprised L-type calcium channels and $\mathrm{CaM}$ are required for channel inactivation and facilitation (Peterson et al., 1999; Zühlke et al., 1999, 2000; Erickson et al., 2001; Pitt et al., 2001). Therefore, by modulating calcium entry through L-type calcium channels, CaM may indirectly influence CREB phosphorylation. Furthermore, after brief stimulation, L-type calcium channelinduced CREB phosphorylation occurs via CaM-dependent pro- 
A

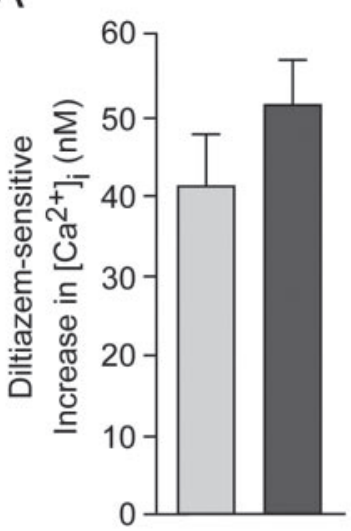

口DHP-LTC

DHP-LTCNOPDZ
B

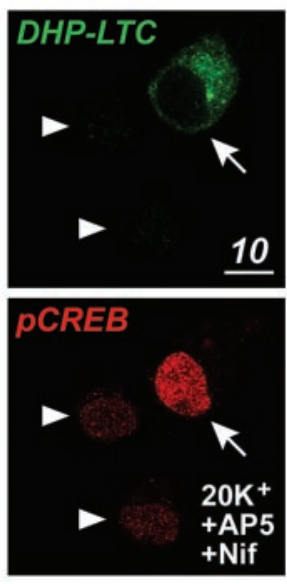

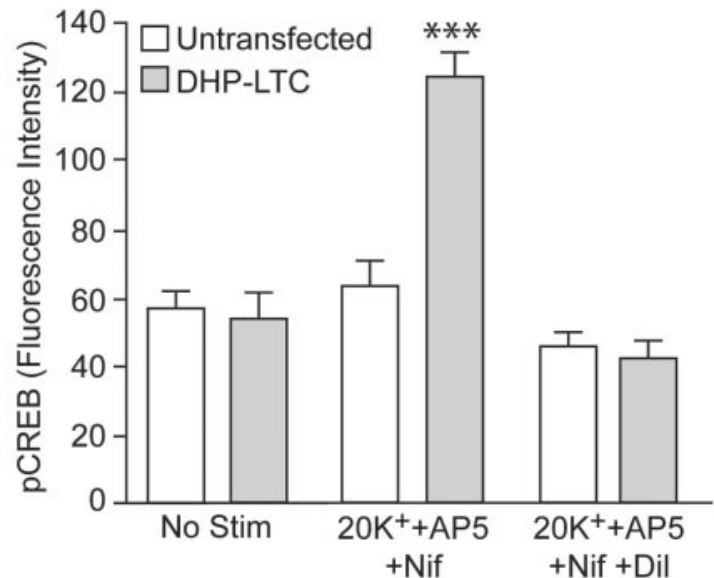

C
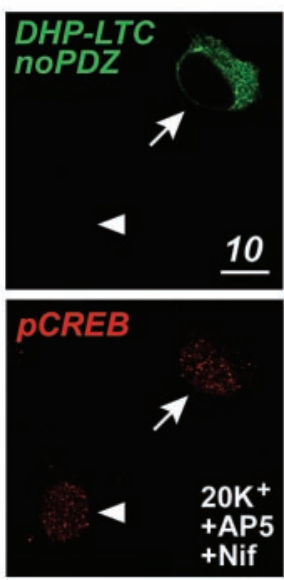

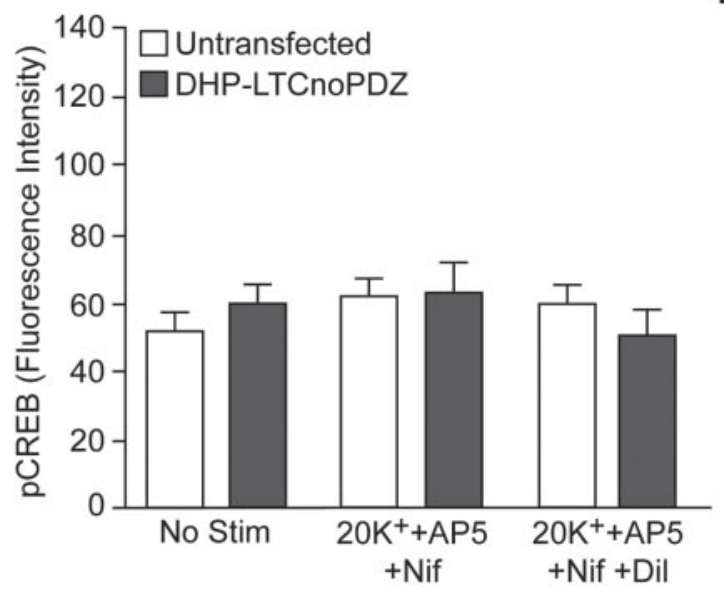

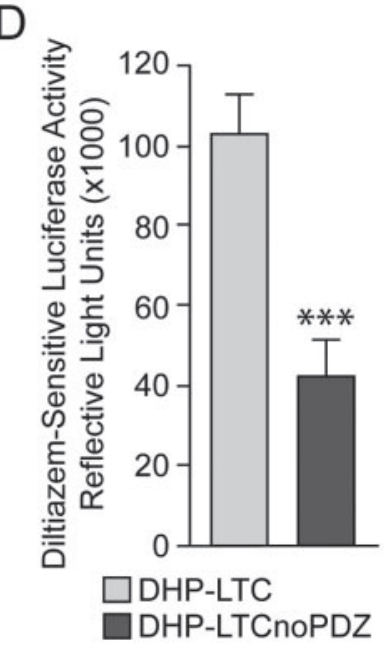

Figure 7. The PDZ interaction sequence on $\alpha_{1}$ is required for L-type calcium channels to effectively signal to CREB. A, Diltiazem-sensitive (100 $\left.\mu \mathrm{M}\right)$ increases in $\left[\mathrm{Ca}^{2+}\right]_{\mathrm{i}}$ after a $3 \mathrm{~min} 20 \mathrm{~mm} \mathrm{~K}{ }^{+}$ ( + AP5 and nifedipine) depolarization are not significantly different between neurons transfected with the full-length, dihydropyridine-insensitive L-type calcium channel (DHP-LTC) and those expressing DHP-LTCnoPDZ. B, Neurons expressing DHP-LTCs (arrow) exhibit significant $(p<0.001)$ increases in CREB phosphorylation after the same stimulation conditions outlined above; untransfected neurons do not (arrowheads). The stimulus-induced increase in CREB phosphorylation was blocked by diltiazem. C, Unlike full-length channels, dihydropyridine-insensitive L-type calcium channels lacking the PDZ interaction sequence do not trigger CREB phosphorylation after a 3 min depolarization. D, In comparison with neurons transfected with DHP-LTC, neurons transfected with DHP-LTCnoPDZ exhibit significantly $(p<0.001)$ less diltiazem-sensitive CRE-dependent transcription after a $3 \mathrm{hr} 20 \mathrm{~mm} \mathrm{~K}^{+}$stimulus in the presence of AP5 and nifedipine.

tein kinase kinase and CaM-dependent protein kinase IV (CaMKIV), indicating that CaM plays a more direct role in CREB activation (Enslen et al., 1995; Tokumitsu et al., 1995; Bito et al., 1996; Ahn et al., 1999; Mermelstein et al., 2001). A necessary step in this process is the translocation of CaM from the cytosol into the nucleus (Deisseroth et al., 1998; Mermelstein et al., 2001; Wei et al., 2002). With longer depolarizations, L-type calcium channels mediate CREB phosphorylation through MAPK (mitogenactivated protein kinase) (Xing et al., 1996; Impey et al., 1998), a process also requiring CaM (Dolmetsch et al., 2001). Consequently, interactions within a clustered signaling complex, in which PDZ domain proteins play a critical role, may ensure that L-type calcium channels have access to sufficient concentrations of CaM to carry out multiple cellular functions.

Outside the hippocampus, the privileged role of L-type calcium channels in CREB signaling has been observed in the cerebral cortex, cerebellum, neostriatum, olfactory bulb, and retina (Murphy et al., 1991; Yoshida et al., 1995; Liu and Graybiel, 1996; Cigola et al., 1998). Calcium entry through NMDA receptors also activates CREB via a mechanism that uses local calcium microdo- mains (Hardingham et al., 2001, 2002). Cooperation between NMDA receptors and L-type calcium channels can occur to enhance CREB signaling (Nakazawa and Murphy, 1999; Rajadhyaksha et al., 1999), but depending on the stimulus conditions, activation of a single pathway can also take place (Hardingham et al., 2002). Our work has focused on studying how mild depolarizations lead to CREB phosphorylation and CRE-dependent transcription via CaM/CaMKIV activation, because this is the signaling pathway responsible for CREB regulation after synaptic activity at multiple stimulus frequencies (Deisseroth et al., 1996) and is a critical mediator of plasticity in vivo (Ho et al., 2000; Ribar et al., 2000).

With the expression of EGFP-VSNL, we were able to differentiate CREB phosphorylation caused by calcium entry through L-type calcium channels from NMDA receptors. But what is the purpose of having both L-type calcium channels and NMDA receptors signal to CREB? One possibility is that along with CREB phosphorylation, each pathway also activates other signaling molecules specific to that particular cascade, resulting in differences between L-type calcium channel- and NMDA receptor- 
mediated plasticity. For example, calcium entry through L-type calcium channels activates NFATc4, whereas calcium through NMDA receptors will not (Graef et al., 1999). Recently, L-type calcium channel-mediated, but not NMDA receptor-mediated, long-term potentiation and long-term depression were altered after disruption of the gene encoding extracellular matrix glycoprotein tenascin-C (Evers et al., 2002). These data further suggest that activation of L-type calcium channels and NMDA receptors lead to distinct aspects of plasticity.

In addition to CREB and NFATc4, L-type calcium channels have been shown to activate the transcription factors serum response factor and myocyte enhancer factor-2 (Misra et al., 1994; Mao et al., 1999). Because NFAT-dependent transcription was not affected by EGFP-VSNL, interactions between PDZ domain proteins and $\alpha_{1 C}$ are apparently not required for linking L-type calcium channels to the second messenger systems that trigger NFATc4 activation. Thus, multiple mechanisms seem to exist by which L-type calcium channels signal changes in gene expression. This adds another layer of cellular complexity to stimulusinduced signaling, because these separate gene activation pathways could be differentially regulated.

Notably, other discrepancies exist between activation of CREB and NFATc4 after the opening of L-type calcium channels. For example, NFATc4 requires dephosphorylation by calcineurin (Rao et al., 1997), previously shown to limit CREB phosphorylation (Bito et al., 1996). CREB and NFATc4 also exhibit differential sensitivities to the patterns of synaptic stimulation used to trigger their responses (P. G. Mermelstein and R. W. Tsien, unpublished observations). Furthermore, calcium entry through NMDA receptors, but not release from intracellular stores, will lead to rapid CREB activation, whereas the opposite is true for NFATc4. What can account for these differences between CREB and NFATc4 activation? One possibility is that NFAT-dependent transcription is being regulated by calcium entry through $\alpha_{1 D^{-}}$ comprised L-type calcium channels. Experiments are under way to address this issue, as well as to determine whether interactions with PDZ domain proteins are required for L-type calcium channels to signal to transcription factors other than CREB.

Understanding how L-type calcium channels regulate different transcription factors is of significant interest, because their coordinated activities guide the expression of immediate-early genes, growth factors, signaling, and structural proteins. Furthermore, through changes in gene expression, L-type calcium channels affect cell fate and axonal and dendritic guidance and influence long-term potentiation and depression (for review, see Mermelstein et al., 2000). The concept of localized calcium signaling within subcellular microdomains has been suggested as a mechanism of signaling specificity for years. Here we provide some of the first evidence that L-type calcium channels signal to the transcription factor CREB using such a process. Further examination of this and other signaling pathways leading to variations in gene expression after L-type calcium channel activation will play an important role in understanding how cellular activity leads to long-term changes in cell structure and function.

\section{References}

Agrawal SK, Nashmi R, Fehlings MG (2000) Role of L- and N-type calcium channels in the pathophysiology of traumatic spinal cord white matter injury. Neuroscience 99:179-188.

Ahn S, Ginty DD, Linden DJ (1999) A late phase of cerebellar long-term depression requires activation of CaMKIV and CREB. Neuron 23:559-568.

Anderson LE, Seybold VS (2000) Phosphorylated cAMP response element binding protein increases in neurokinin-1 receptor-immunoreactive neurons in rat spinal cord in response to formalin-induced nociception. Neurosci Lett 283:29-32.

Bading H, Ginty DD, Greenberg ME (1993) Regulation of gene expression in hippocampal neurons by distinct calcium signaling pathways. Science 260:181-186.

Bito H, Deisseroth K, Tsien RW (1996) CREB phosphorylation and dephosphorylation: $\mathrm{a} \mathrm{Ca}(2+)$ - and stimulus duration-dependent switch for hippocampal gene expression. Cell 87:1203-1214.

Bonni A, Greenberg ME (1997) Neurotrophin regulation of gene expression. Can J Neurol Sci 24:272-283.

Carlezon Jr WA, Thome J, Olson VG, Lane-Ladd SB, Brodkin ES, Hiroi N, Duman RS, Neve RL, Nestler EJ (1998) Regulation of cocaine reward by CREB. Science 282:2272-2275.

Chung YH, Shin CM, Kim MJ, Cha CI (2001) Enhanced expression of L-type $\mathrm{Ca}^{2+}$ channels in reactive astrocytes after ischemic injury in rats. Neurosci Lett 302:93-96.

Cigola E, Volpe BT, Lee JW, Franzen L, Baker H (1998) Tyrosine hydroxylase expression in primary cultures of olfactory bulb: role of L-type calcium channels. J Neurosci 18:7638-7649.

Craven SE, Bredt DS (1998) PDZ proteins organize synaptic signaling pathways. Cell 93:495-498.

Deisseroth K, Bito H, Tsien RW (1996) Signaling from synapse to nucleus: postsynaptic CREB phosphorylation during multiple forms of hippocampal synaptic plasticity. Neuron 16:89-101.

Deisseroth K, Heist EK, Tsien RW (1998) Translocation of calmodulin to the nucleus supports CREB phosphorylation in hippocampal neurons. Nature 392:198-202.

Dolmetsch RE, Pajvani V, Fife K, Spotts J, Greenberg ME (2001) Signaling to the nucleus by and L-type calcium channel-calmodulin complex through the MAP kinase pathway. Science 294:333-339.

Enslen H, Tokumitsu H, Soderling TR (1995) Phosphorylation of CREB by CaM-kinase IV activated by CaM-kinase IV kinase. Biochem Biophys Res Commun 207:1038-1043.

Erickson MG, Alseikhan BA, Perterson BZ, Yue DT (2001) Preassociation of calmodulin with voltage-gated $\mathrm{Ca}^{2+}$ channels revealed by FRET in single living cells. Neuron 31:973-985.

Evers MR, Salmen B, Bukalo O, Rollenhagen A, Bosl MR, Morellini F, Bartsch U, Dityatev A, Schachner M (2002) Impairment of L-type $\mathrm{Ca}^{2+}$ channel-dependent forms of hippocampal synaptic plasticity in mice deficient in the extracellular matrix glycoprotein tenascin-C. J Neurosci 22:7177-7194.

Finkbeiner S, Tavazoie SF, Maloratsky A, Jacobs KM, Harris KM, Greenberg ME (1997) CREB: a major mediator of neuronal neurotrophin responses. Neuron 19:1031-1047.

Ginty DD, Kornhauser JM, Thompson MA, Bading H, Mayo KE, Takahashi JS, Greenberg ME (1993) Regulation of CREB phosphorylation in the suprachiasmatic nucleus by light and a circadian clock. Science 260:238-241.

Graef IA, Mermelstein PG, Stankunas K, Neilson JR, Deisseroth K, Tsien RW, Crabtree GR (1999) L-type calcium channels and GSK-3 regulate the activity of NF-ATc4 in hippocampal neurons. Nature 401:703-708.

Grynkiewicz G, Poenie M, Tsien RY (1985) A new generation of $\mathrm{Ca}^{2+}$ indicators with greatly improved fluorescence properties. J Biol Chem 260:3440-3450.

Hardingham GE, Arnold FJ, Bading H (2001) A calcium microdomain near NMDA receptors: on switch for ERK-dependent synapse-to-nucleus communication. Nat Neurosci 4:565-566.

Hardingham GE, Fukunaga Y, Bading H (2002) Extrasynaptic NMDARs oppose synaptic NMDARs by triggering CREB shut-off and cell death pathways. Nat Neurosci 5:405-414.

Harlow E, Lane D (1988) Antibodies: a laboratory manual. Cold Spring Harbor, NY: Cold Spring Harbor Laboratory.

Hell JW, Westenbroek RE, Warner C, Ahlijanian MK, Prystay W, Gilbert MM, Snutch TP, Catterall WA (1993) Identification and differential subcellular localization of the neuronal class $C$ and class D L-type calcium channel $\alpha_{1}$ subunits. J Cell Biol 123:949-962.

Ho N, Liauw JA, Blaeser F, Wei F, Hanissian S, Muglia LM, Wozniak DF, Nardi A, Arvin KL, Holtzman DM, Linden DJ, Zhuo M, Muglia LJ, Chatila TA (2000) Impaired synaptic plasticity and cAMP response element-binding protein activation in $\mathrm{Ca}^{2+} /$ calmodulin-dependent protein kinase type IV/Gr-deficient mice. J Neurosci 20:6459-6472.

Ihara Y, Yamada Y, Fujii Y, Gonoi T, Yano H, Yasuda K, Inagaki N, Seino Y, 
Seino S (1995) Molecular diversity and functional characterization of voltage- dependent calcium channels (CACN4) expressed in pancreatic beta-cells. Mol Endocrinol 9:121-130.

Impey S, Obrietan K, Wong ST, Poser S, Yano S, Wayman G, Deloulme JC, Chan G, Storm DR (1998) Cross talk between ERK and PKA is required for $\mathrm{Ca}^{2+}$ stimulation of CREB-dependent transcription and ERK nuclear translocation. Neuron 21:869-883.

Impey S, Fong AL, Wang Y, Cardinaux JR, Fass DM, Obrietan K, Wayman GA, Storm DR, Soderling TR, Goodman RH (2002) Phosphorylation of CBP mediates transcriptional activation by neural activity and CaM kinase IV. Neuron 34:235-244.

Ji RR, Rupp F (1997) Phosphorylation of transcription factor CREB in rat spinal cord after formalin-induced hyperalgesia: relationship to c-fos induction. J Neurosci 17:1776-1785.

Kaneko S, Cooper CB, Nishioka N, Yamasaki H, Suzuki A, Jarvis SE, Akaike A, Satoh M, Zamponi GW (2002) Identification and characterization of novel human $\mathrm{Ca}(\mathrm{v}) 2.2(\alpha 1 \mathrm{~B})$ calcium channel variants lacking the synaptic protein interaction site. J Neurosci 22:82-92.

Kang H, Sun LD, Atkins CM, Soderling TR, Wilson MA, Tonegawa S (2001) An important role of neural activity-dependent CaMKIV signaling in the consolidation of long-term memory. Cell 106:771-783.

Koch WJ, Ellinor PT, Schwartz A (1990) cDNA cloning of a dihydropyridinesensitive calcium channel from rat aorta. Evidence for the existence of alternatively spliced forms. J Biol Chem 265:17786-17791.

Kurschner C, Yuzaki M (1999) Neuronal interleukin-16 (NIL-16): a dual function PDZ domain protein. J Neurosci 19:7770-7780.

Kurschner C, Mermelstein PG, Holden WT, Surmeier DJ (1998) CIPP, a novel multivalent PDZ domain protein, selectively interacts with Kir4.0 family members, NMDA receptor subunits, neurexins, and neuroligins. Mol Cell Neurosci 11:161-172.

Lanahan A, Worley P (1998) Immediate-early genes and synaptic function. Neurobiol Learn Mem 70:37-43.

Latour I, Gee CE, Robitaille R, Lacaille JC (2001) Differential mechanisms of $\mathrm{Ca}^{2+}$ responses in glial cells evoked by exogenous and endogenous glutamate in rat hippocampus. Hippocampus 11:132-145.

Lee A, Wong ST, Gallagher D, Li B, Storm DR, Scheuer T, Catterall WA (1999) $\mathrm{Ca}^{2+} /$ calmodulin binds to and modulates P/Q-type calcium channels. Nature 399:155-159.

Liu FC, Graybiel AM (1996) Spatiotemporal dynamics of CREB phosphorylation: transient versus sustained phosphorylation in the developing striatum. Neuron 17:1133-1144.

Mao Z, Bonni A, Xia F, Nadal-Vicens M, Greenberg ME (1999) Neuronal activity-dependent cell survival mediated by transcription factor MEF2. Science 286:785-790.

Maximov A, Bezprozvanny I (2002) Synaptic targeting of N-type calcium channels in hippocampal neurons. J Neurosci 22:6939-6952.

Maximov A, Sudhof TC, Bezprozvanny I (1999) Association of neuronal calcium channels with modular adaptor proteins. J Biol Chem 274:24453-24456.

Melzack R, Coderre TJ, Katz J, Vaccarino AL (2001) Central neuroplasticity and pathological pain. Ann NY Acad Sci 933:157-174.

Mermelstein PG, Bito H, Deisseroth K, Tsien RW (2000) Critical dependence of cAMP response element-binding protein phosphorylation on L-type calcium channels supports a selective response to EPSPs in preference to action potentials. J Neurosci 20:266-273.

Mermelstein PG, Deisseroth K, Dasgupta N, Isaksen AL, Tsien RW (2001) Calmodulin priming: nuclear translocation of a calmodulin complex and the memory of prior neuronal activity. Proc Natl Acad Sci USA 98:15342-15347.

Milner B, Squire LR, Kandel ER (1998) Cognitive neuroscience and the study of memory. Neuron 20:445-468.

Misra RP, Bonni A, Miranti CK, Rivera VM, Sheng M, Greenberg ME (1994) L-type voltage-sensitive calcium channel activation stimulates gene expression by a serum response factor-dependent pathway. J Biol Chem 269:25483-25493.

Morgan JI, Curran T (1991) Stimulus-transcription coupling in the nervous system: involvement of the inducible proto-oncogenes fos and jun. Annu Rev Neurosci 14:421-451.

Murphy TH, Worley PF, Baraban JM (1991) L-type voltage-sensitive calcium channels mediate synaptic activation of immediate early genes. Neuron 7:625-635.
Nakazawa H, Murphy TH (1999) Activation of nuclear calcium dynamics by synaptic stimulation in cultured cortical neurons. J Neurochem 73:1075-1083.

Nestler EJ, Aghajanian GK (1997) Molecular and cellular basis of addiction. Science 278:58-63.

Parker D, Ferreri K, Nakajima T, LaMorte VJ, Evans R, Koerber SC, Hoeger C, Montminy MR (1996) Phosphorylation of CREB at Ser-133 induces complex formation with CREB-binding protein via a direct mechanism. Mol Cell Biol 16:694-703.

Peterson BZ, DeMaria CD, Adelman JP, Yue DT (1999) Calmodulin is the $\mathrm{Ca}^{2+}$ sensor for $\mathrm{Ca}^{2+}$-dependent inactivation of L-type calcium channels. Neuron 22:549-558.

Pitt GS, Zuhlke RD, Hudmon A, Schulman H, Reuter H, Tsien RW (2001) Molecular basis of calmodulin tethering and $\mathrm{Ca}^{2+}$-dependent inactivation of L-type $\mathrm{Ca}^{2+}$ channels. J Biol Chem 276:30794-30802.

Rajadhyaksha A, Barczak A, Macías W, Leveque JC, Lewis SE, Konradi C (1999) L-Type $\mathrm{Ca}\left({ }^{2+}\right)$ channels are essential for glutamate-mediated CREB phosphorylation and c-fos gene expression in striatal neurons. J Neurosci 19:6348-6359.

Rao A, Luo C, Hogan PG (1997) Transcription factors of the NFAT family: regulation and function. Annu Rev Immunol 15:707-747.

Ribar TJ, Rodriguiz RM, Khiroug L, Wetsel WC, Augustine GJ, Means AR (2000) Cerebellar defects in $\mathrm{Ca}^{2+} /$ calmodulin kinase IV-deficient mice. J Neurosci 20:RC107(1-5).

Safa P, Boulter J, Hales TG (2001) Functional properties of Cav1.3 (alpha1D) L-type Ca2 + channel splice variants expressed by rat brain and neuroendocrine GH3 cells. J Biol Chem 276:38727-38737.

Sheng M, Pak DTS (2000) Ligand-gated ion channel interactions with cytoskeletal and signaling proteins. Annu Rev Physiol 62:755-778.

Sheng M, Thompson MA, Greenberg ME (1991) CREB: a Ca ${ }^{2+}$-regulated transcription factor phosphorylated by calmodulin-dependent kinases. Science 252:1427-1430.

Silva AJ, Kogan JH, Frankland PW, Kida S (1998) CREB and memory. Annu Rev Neurosci 21:127-148.

Snutch TP, Tomlinson WJ, Leonard JP, Gilbert MM (1991) Distinct calcium channels are generated by alternative splicing and are differentially expressed in the mammalian CNS. Neuron 7:45-57.

Tokumitsu H, Enslen H, Soderling TR (1995) Characterization of a $\mathrm{Ca}^{2+}$ / calmodulin-dependent protein kinase cascade. Molecular cloning and expression of calcium/calmodulin-dependent protein kinase kinase. J Biol Chem 270:19320-19324.

Wei F, Qiu CS, Liauw J, Robinson DA, Ho N, Chatila T, Zhuo M (2002) Calcium calmodulin-dependent protein kinase IV is required for fear memory. Nat Neurosci 5:573-579.

Werth JL, Usachev YM, Thayer SA (1996) Modulation of calcium efflux from cultured rat dorsal root ganglion neurons. J Neurosci 16:1008-1015.

Westenbroek RE, Ahlijanian MK, Catterall WA (1990) Clustering of L-type $\mathrm{Ca}^{2+}$ channels at the base of major dendrites in hippocampal pyramidal neurons. Nature 347:281-284.

Wu GY, Deisseroth K, Tsien RW (2001) Activity-dependent CREB phosphorylation: convergence of a fast, sensitive calmodulin kinase pathway and a slow, less sensitive mitogen-activated protein kinase pathway. Proc Natl Acad Sci USA 98:2808-2813.

Xing J, Ginty DD, Greenberg ME (1996) Coupling of the RAS-MAPK pathway to gene activation by RSK2, a growth factor-regulated CREB kinase. Science 273:959-963.

Xu W, Lipscombe D (2001) Neuronal Ca(V)1.3 $\alpha(1)$ L-type channels activate at relatively hyperpolarized membrane potentials and are incompletely inhibited by dihydropyridines. J Neurosci 21:5944-5951.

Yoshida K, Imaki J, Matsuda H, Hagiwara M (1995) Light-induced CREB phosphorylation and gene expression in rat retinal cells. J Neurochem 65:1499-1504.

Zühlke RD, Pitt GS, Deisseroth K, Tsien RW, Reuter H (1999) Calmodulin supports both inactivation and facilitation of L-type calcium channels. Nature 399:159-162.

Zühlke RD, Pitt GS, Tsien RW, Reuter H (2000) $\mathrm{Ca}^{2+}$-sensitive inactivation and facilitation of L-type $\mathrm{Ca}^{2+}$ channels both depend on specific amino acid residues in a consensus calmodulin-binding motif in the(alpha) $1 \mathrm{C}$ subunit. J Biol Chem 275:21121-21129. 